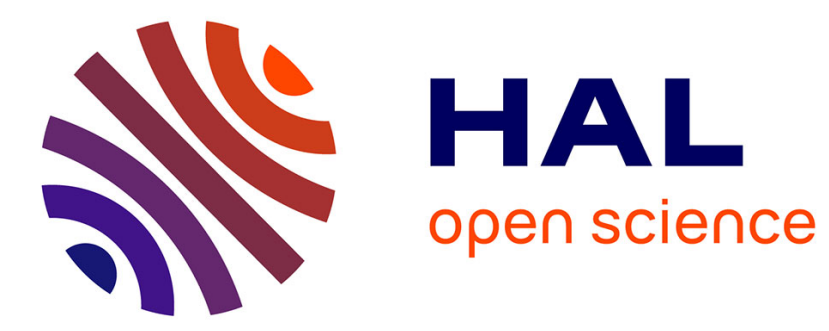

\title{
Does The Consensus Prevail? Experimental Evidence Sylvain Marsat
}

\section{To cite this version:}

Sylvain Marsat. Does The Consensus Prevail? Experimental Evidence. 2006. hal-02156562

\section{HAL Id: hal-02156562 \\ https://hal.science/hal-02156562}

Preprint submitted on 14 Jun 2019

HAL is a multi-disciplinary open access archive for the deposit and dissemination of scientific research documents, whether they are published or not. The documents may come from teaching and research institutions in France or abroad, or from public or private research centers.
L'archive ouverte pluridisciplinaire HAL, est destinée au dépôt et à la diffusion de documents scientifiques de niveau recherche, publiés ou non, émanant des établissements d'enseignement et de recherche français ou étrangers, des laboratoires publics ou privés. 


\title{
Does The Consensus Prevail? Experimental Evidence
}

\author{
Sylvain Marsat \\ Clermont University
}

\begin{abstract}
We test hypotheses on herd behavior in a simple investment decision through an experimental setting. Subjects were given some fundamental information about a specific firm and asked for a recommendation, buy or sell. This personal judgment was then confronted to the opposed consensus of analysts, in order to determine if subjects revise their recommendations. In this binary choice setting, we show that herding takes place, and is inversely correlated to perceived individual ability. Moreover, when reputation is at stake, conformist subjects are even more prone to follow the consensus in their decision making.
\end{abstract}

Key Words: Herding Behavior; Decision Making; Behavioral Finance; Reputation

Herding behavior is, among other behavioral biases, a frequently cited phenomenon by both money managers and academics to explain booms and crashes in financial markets (Denevow and Welch [1996]). Sometimes, agents on the market are presumed to act according to the behavior of others. Although such behavior is often analyzed in the literature (e.g. Scharfstein and Stein [1990], Bikhchandani, Hirshleifer and Welch [1992], Graham [1999], or Chamley [2004]), empiric evidence is still quite scarce (Welch [2000]). Since Lakonishok, Shleifer, and Vishny [1992], many works (e.g. Wermers [1999], Wylie [2005]) have tried to show clusters among individuals, who act together on the market, compared to a "normal" behavior. However, most of these studies are not convincing since they come up against the detection of actual herding. The fact that individuals acted in the same manner is not always the consequence of herding, and can merely be a common reaction to a common

\footnotetext{
Adress correspondence to Sylvain Marsat, Clermont University, Faculté de Sciences Economiques et de Gestion, 41 Boulevard François Mitterrand, F-63 002 Clermont-Fd Cedex, France.

Email : sylvain.marsat@u-clermont1.fr

Software used : SPSS 12.0
} 
constraint or to some information, just as people open their umbrellas because of rain, and not because others have opened theirs (Weber [1968]).

Genuine herding behavior cannot, therefore, really be pinpointed without knowledge of the information set used by each actor. As suggested by Graham [1999], experimentation appears to be a convenient method to control this information set. The stream initiated by Anderson and Holt $[1997]^{1}$ reveals evidence on informational cascades in very simplified environments. The asset is presented as a state of nature, and information signals are designed by urns holding a proportion of indicators on this state ${ }^{2}$. This probabilistic environment seems, however, rather far from a real financial decision, which involves more complex information.

Cote and Sanders [1997] propose an original methodology to avoid this problem. They study the impact of the consensus on subjects' earnings predictions. Individuals have access to an information set and make a forecast of their earnings for the following year. After this forecast has been made, they are given a consensus of analysts, and they can revise their estimations. The authors found that the consensus significantly influenced the subsequent forecast. This influence was stronger when subjects found the consensus credible, and when they had little confidence in their own ability.

Unlike these authors who analyze herding behavior in a continuous choice setting, the bulk of academic works, including seminal models from Bikhchandani, Hirshleifer and Welch [1992] or Scharfstein and Stein [1990], are based on a binary signal and dichotomous choice setting. Here, herding behavior is not defined loosely as a choice closer to the consensus, but rather, in a much more restrictive manner, as when individuals give up their own signal to follow one or more agents, such as the consensus of analysts.

The aim of this experiment is to adapt Cote and Sanders' [1997] design, in order to study herding in a simple dichotomous financial choice setting, i.e. when people totally disregard 
their own judgment to follow the group. To the best of our knowledge, this is the first attempt (i) to actually test binary herding and its determinants in a close-to-real financial setting and (ii) to study reputational and informational factors in combination. Indeed, reputation, which has not been introduced as an external constraint by experimental research so far, is included.

We find clear empiric evidence of herding behavior in this framework. Herding is proved to be correlated to the inclusion of reputation (especially for conformist subjects), and inversely correlated to subjects' perceived abilities. This paper is organized as follows. The first section examines some of the major academic explanation in the literature explaining herding behavior tested in this experiment. The methodology is then described in a second section, and the main results are presented and analyzed in the last section.

\section{FACTORS EXPLAINING HERDING BEHAVIOR}

Numerous studies in experimental psychology present evidence of group influence upon individual decision making. Sherif [1936] reveals that, in an ambiguous situation created by the autokinetic effect, subjects converge in their estimations towards the norm that emerges from the group. Asch [1951] challenges the perception of the length of lines: in the presence of other subjects that give a clear erroneous estimation, around 32 percent of the subjects follow and make the same incorrect choice.

Deutsch and Gerard [1955] distinguish two different kinds of group pressure: informational influence which occurs when people believe that the information transmitted by other is true, and normative influence which occurs when they conform in order to be rewarded by others. If these authors show that, in an anonymous environment, normative influence is less significant, Crutchfield [1955] notes that between 25 and 30 percent of the subjects in his experiment still admit to having made the same choice as others, even though they believed that it was not the right choice, thus exhibiting deliberate non-informational conformism. 
On financial markets, these two streams have been studied using economic modeling. Informational reasons are analyzed in the famous paper by Bikhchandani, Hirshleifer and Welch [1992], but also Banerjee [1992], Kirman [1993], Avery and Zemsky [1998], or Chamley [2004]. On the other hand, Scharfstein and Stein [1990], Trueman [1990], Avery and Chevalier [1999] or Graham [1999] present models of normative or reputational herding. Ottaviani and Sorensen [2000] underline that herding might arise from the interaction of these two streams. These studies enable us to structure empirically testable hypotheses in a financial environment.

In their seminal model, Bikhchandani, Hirshleifer and Welch [1992] emphasize the role of information quest as a major factor in herding. In this framework, an agent imitates previous ones when he believes that they are better informed than himself. Thus, when every agent has the same signal reliability, $p$, if two previous agents acted the same way, the third rationally follows, disregarding his own information and a cascade occurs. If reliability is not the same for every agent, an actor having a low precision signal will logically be more inclined to herd.

$\mathbf{H}_{1}$ : The lower the perception of reliability of the private signal by the agent, the greater his tendency to herd.

Lamont [1995], Chevalier and Ellison [1999] or Hong and al. [2000] argue that more experienced decision makers are less prone to herd. An agent could receive a very precise signal and feel a priori incompetent to interpret it properly. In a continuous choice setting, Cote and Sanders [1997] show that subjects that are less confident in their abilities prove to be more easily influenced by the consensus. Therefore, an agent's level of confidence in his own capacities might play an important role in his, even binary, herding behavior.

$\mathbf{H}_{2}$ : The lower the agent's a priori confidence in his own capacities, the greater his tendency to herd. 
Cote and Sanders [1997] note that perception of other actors' abilities is often cited in social psychology studies (e.g. Bochner and Insko [1966], Aronson and al. [1963], Blacke and al. [1957]). For instance, a highly respected and famous analyst should have more impact on money managers than his younger counterpart. Similarly, if the consensus of analysts is perceived a priori to be highly credible, he should have an even greater impact the decisionmaking.

$\mathbf{H}_{3}$ : The higher the agent's a priori confidence in the abilities of the analysts, the greater his tendency to herd.

The proportion of analysts making the same recommendation may also have an influence (Wilder [1977]). In their study on several experiments based on Anderson and Holt's [1998] probabilistic environment, Kübler and Weizsäcker [2005] show that a positive correlation can be proved between the length of the cascade and its strength. The more a significant number of agents have made the same decision, the greater the probability the next agent follows.

$\mathbf{H}_{4}$ : The higher the majority of analysts agree on a recommendation, the greater an agent's tendency to herd.

Since Keynes [1936], and more recently Scharfstein and Stein [1990], reputation is often cited in explaining herding behaviors (Graham [1999], Avery and Chevalier [1999], Dasgupta and Prat [2006], or Ottaviani and Sorensen [2006]). The manager acts, not to optimize his decision in an informational manner, but in order to protect his reputation, and to avoid being judged as incompetent. As a matter of fact, it is difficult to objectively judge the ability of managers on financial markets, insofar as their performance is highly affected by random components. The best way to evaluate their ability could be to compare their actions with those of theirs peers, postulating that the majority is correctly informed.

$\mathbf{H}_{5}$ : The more the agent tries to protect his reputation, the greater his tendency to herd. 
For Shiller [1984], investing is a social activity since investors discuss their choices, read about them, and gossip about other investors' successes or failures. Social psychology studies, (e.g. Asch [1951], Crutchfield [1955]) show that in everyday some individuals are more prone to follow the majority than others life. They exhibit a more conformist personality, and their behaviors are generally close to the group. Of course, this conformism might also influence their investment choice.

$\mathbf{H}_{6}$ : The more the agent is proved to be conformist, the greater his tendency to herd.

Briefly, herding behavior should be correlated with the perception of analysts' abilities, the proportion of analysts who agree on a recommendation, the protection of reputation and individual conformism. On the other hand, a high reliability of the information signal and confidence in individual capacities should be negatively correlated with this behavior. Although these hypotheses receive strong theoretical support, most of them are poorly experimentally tested in a financial environment. Indeed, econometric methodologies are unable to detect real herding, and experimental studies seem far removed from a real investment.

We capitalize on Cote and Sanders' [1997] experiment which tests the impact of the consensus of analysts on individual decision making. Our experimental design, however, is more restrictive, since we only consider herding when subjects really give up their own opinion to follow the consensus of analysts. Moreover, we add an external reputational constraint to test its influence on the decision. The next section describes the methodology used in the experiment.

\section{METHODOLOGY}

Experimentation seems to be a convenient manner to control the information set of each actor, and to discriminate herding from correlated behaviors (Graham [1999]). This constraint is not possible in situ, on financial markets. 


\section{Experimental design}

In order to isolate an actual herding behavior, the subject's initial choice has to be opposed to that of the consensus. The information given to the subjects was selected with a screening process using JCFQuant-Factset database, which is widely used among portfolio managers. Two different French firms were selected in order to satisfy three criteria:

1. have ratios (including P/E and Price to book ratios) over- or under-valued compared to the market, as well as to their industry sector ${ }^{3}$;

2. be in the mid- and small-caps companies, so as not to be recognized by subjects. All companies recently in the news have been put aside;

3. are not "high technology" companies, including information and communication, since the recent internet bubble might have induced biased behaviors.

The data submitted to subjects are real data from the JCFQuant-Factset database, with complementary information from annual reports of the companies. The two French companies chosen have been called $\mathrm{X}$ and $\mathrm{Y}$. No subject recognized them.

The questionnaire was divided into three parts ${ }^{4}$. The first and the third parts correspond to demographic questions as well as measures of indicators concerning the hypotheses. The experiment, in the second part, was split into three stages.

In the first step, an information set on the firm is submitted: a brief general presentation, industry statistics, evolution of sales, profits and EBIT, balance sheet, income statement as well as major ratios over the previous four years. The comparison between a firm's ratios and the industry indicated an over- or under-priced firm. With this information set, subjects were asked to make a buy or sell recommendation and to reveal their level of confidence in this choice.

In stage 2, new information is submitted to subjects: 
1. a consensus of analysts, which was manipulated in order to be opposed to the over- or under-pricing revealed in stage 1.

2. a five-year financial summary, which a priori conveyed no more information than given in the first stage ${ }^{5}$. As highlighted by Cote and Sanders [1997], this report is added because the consensus alone may trigger demand effects and hypothetical guessing.

With data from stage 1 and this new additional information, subjects had to make a second recommendation and indicate their confidence in their choice.

At stage 3, no new information was submitted to subjects. The decision rule is, however, different since a reputation constraint is introduced, according to Scharftein and Stein [1990]. If the personal recommendation diverges from that of the analysts, the portfolio manager will be the only one to support a bad choice, and be judged incapable by his clients and hierarchy. On the other hand, making a bad decision with the majority enables the manager to "share the blame" with others. With this new constraint, subjects gave a third recommendation and the level of confidence in this choice.

\section{Measuring the hypotheses}

Parts 1 and 3 of the questionnaire are designed to collect data in order to interpret the results of the experiment, according to the hypotheses presented. The a priori perception of individual ability and that of other agents should play an important role in the decision. To measure this confidence, diverse scales could have been used. Following Cote and Sanders [1997], the Lichtenstein and Bearden [1989] scale measuring source credibility has been chosen to gauge a priori the perception of the level of confidence of subjects in their own capacities, as well as the confidence they place in financial analysts. Before being given any information on the firm, subjects were asked to locate this confidence on a seven point Likert scale, rating the analysis as (1) dependable, (2) credible, (3) accurate and (4) trustworthy. 
All the subjects had access to the same information in stage 1: whether on firm $\mathrm{X}$ or on firm Y. However, all subjects may not have had the same perception of this signal. Therefore, reliability was assessed using a seven point Likert scale, in which subjects rated the information given as (1) precise, (2) easy to interpret, (3) reliable and (4) exhaustive.

Conformism is a difficult personality trait to assess a priori. The scale coined by Pettigrew [1958] in psychology seems the most reliable and is widely used. On a seven point Likert scale, subjects had to assess their agreement (1: "not agree", 7: "totally agree") with affirmations trying to evaluate their personality when facing other agents opposite behavior.

As opposed to the previous hypotheses which rely on individual characteristics, the proportion of the majority was a manipulated variable. Two modalities of this factor were submitted to the subjects. Each firm was presented in stage 2 as being rated by seven analysts. In the strong majority case, six analysts recommended the opposite choice compared to a fundamental point of view in stage 1, while one analyst agreed with the common choice. In the weak majority case, four analysts were opposed to a fundamental choice whereas three other agreed with it.

\section{Experimental procedure}

The experiment took place in February 2006. The entire procedure was respected meticulously in order to preserve the reproduction of this research. When presenting the instructions, the goal presented was to better understand the information used in an investment decision. The questionnaire was presented as being important for research and had to be filled out carefully. After asking for any questions, subjects were not allowed to communicate with each other during the experiment. Before distributing the questionnaire, it was stressed that subjects had to respond to the questions sequentially, and that the data was different for two people sitting side by $\operatorname{side}^{6}$. These subjects were reminded of the 
instructions on the page one of the document. The average duration of the experiment was 35 minutes.

Overall, 158 subjects from five different programs filled out this questionnaire. Four documents were not fully completed. The questionnaires in which the first recommendation corresponds to the consensus of analysts (49) were also set aside because they cannot clearly show a herding behavior, since these subjects do not rely on fundamentals for their recommendation. Of the remaining questionnaires, 17 were excluded since the subjects were aware of the goal of this experiment and, knowing the hypotheses, could therefore have modified their choice.

88 questionnaires have been statistically processed. The subjects chosen for this experiment were students in first and second year of a Master's degree, with a high level of competence in their finance or accounting specialty. Their education and training had provided them with a good knowledge of firm evaluation techniques. In addition, some had experience of financial markets: 53 subjects declared having managed a virtual portfolio and 23 had already personally bought real stocks. There were four different questionnaires, with two firms (X and $\mathrm{Y}$ ) and two levels of consensus (high and low, coded respectively 1 and 2).

\section{Coding of the variables}

Herding behavior has been coded in two different manners. In order to measure herding, which can be either a buy or a sell recommendation (depending on $\mathrm{X}$ and $\mathrm{Y}$ ), a variable HERD2 was created, with two values: 1 if the subject imitates the consensus in stage 2 , and 0 otherwise. HERD3 is identical, concerning the choice with regard to reputation, in stage 3.

To precisely measure the inclination to herd, three variables called ICONF1, ICONF2 and ICONF3 were created, corresponding to the confidence index of the subject in his recommendation. When his recommendation is opposed to the consensus, ICONF has been coded between -1 to -7 according to the Likert scale of confidence in the decision. On the 
other hand, when the choice is to follow the consensus, the confidence has been, symmetrically, coded from 1 to 7 . Hence, a subject who is very confident in a herding choice is close to 7 , whereas a subject who is very confident in a fundamental decision is close to -7 . This coding enables us to consider both the choice made by the subject and the confidence attributed to this recommendation.

\section{RESULTS OF THE EXPERIMENT}

\section{The influence of the consensus}

Before analyzing the choices made by subjects, studying the impact of the consensus on their perception of the firm they had to evaluate is particularly interesting. They were asked to show, on a seven point Likert scale, if they thought that the performance of the stocks (for the next 12 months) would be below, above, or at the same level as the market. Before knowing the consensus, estimations of the firms rely on fundamentals and show firm $\mathrm{X}$ overpriced (performance is presumed to be worse than the market in the future) whereas firm $\mathrm{Y}$ is under-priced. The consensus is manipulated in order to be opposed to this estimation: the majority of the analysts recommend buying stocks in $\mathrm{X}$, and selling stocks in $\mathrm{Y}$. This impacts greatly on the perception of subjects.

The performance estimated by subjects after seeing the consensus is far closer to the mean. The mean of the estimations for firm X rises from 2.86 to 3.60 whereas they fall from 4.61 to 4.46 for $\mathrm{Y}$. The difference in perception is significant $(\mathrm{F}(1,86)=14.38, \mathrm{p}<0.000)$. It is interesting to notice that perception for firm $\mathrm{Y}$ is less affected than for firm $\mathrm{X}$. This could be explained by the industry, since $\mathrm{Y}$ belongs to the automotive industry whereas $\mathrm{X}$ does research and development in the pharmaceutical industry, which can be considered as a more uncertain industry.

\section{Evidence of herding behavior}


There were diverse written reactions to justify the decision. One subject noted: "I'm rational, therefore I follow the analysts". Another one wrote: "they are only analysts". The consensus had different impacts on the choices made. Of 88 subjects, whose personal analysis differs from the consensus in the first recommendation, 25 chose to set their own opinion aside, and followed the majority of analysts in stage 2 . When reputation is introduced in stage 3 , most of the subjects who followed the analysts before did not change position ${ }^{7} .21$ subjects who did not herd for informal reasons, however, decided that it was a better choice to follow the consensus to preserve reputation. Overall, 46 subjects, who initially had a different opinion from the consensus, chose to give up this opinion and to follow the analysts. On the other hand, 42 never followed the consensus choice and maintained their own analysis on the two recommendations. In keeping with the perception of performance, subjects analyzing firm $\mathrm{X}$ were a little more prone to herd than those with firm $\mathrm{Y}$, even if the difference was not significant ${ }^{8}$.

Some of the subjects acknowledged the importance of the consensus in their decision: 18 mentioned it as one of the three most important pieces of information, but only in 4 cases as the most important. Most of them do not mention the consensus, and refer to fundamental information as the motivating factor in their choice. Several explanations are possible. The consensus might have led them to search within fundamental data for some information confirming this point of view. Admitting to following the analysts may be thought to reveal their incompetence, and so was possibly avoided by some of them. In their study, Northcraft and Neale [1987] invited experts and amateurs to visit a house for 20 minutes and gave them a 10-page document on the house, and the ones in the area. They were then invited to make an estimation of the price. This estimation proved to be influenced by the prices of other houses mentioned in the document, but, during the experiment, only 8 percent of the experts and 9 percent of amateur subjects acknowledged that this point was one of their three major 
evaluation criteria. Similarly, a large part of the influence of the consensus is not spontaneously admitted to by the subjects of this experiment.

\section{Evolution of the confidence in the decision}

The ICONF variables indicate the level of confidence of the subject in his choice. When ICONF is negatively coded, the subject has confidence in a fundamental behavior, opposed to herding. Each subject has been selected to adopt a fundamental behavior in stage 1. The introduction of the consensus modifies the mean confidence in a fundamental choice, whose mean goes from -4.15 before the consensus (ICONF1), to -1.93 (ICONF2) afterwards.

The median is almost stable between ICONF1 and ICONF2. Subjects who had a high level of confidence in their fundamental evaluation seem not to be influenced by the consensus. On the other hand, subjects who doubted their decisions (ICONF between -3 and 1) have been largely more influenced by analysts. The introduction of reputation shifts the average confidence to -0.41 , which is very close to the equilibrium between herding and fundamental behaviors. In this case, however, the median is significantly higher, and some subjects who had placed a lot of confidence in their own judgment have consciously decided to change position in order to preserve the reputation of the portfolio manager.

The subjects who herded during stage 3 (ICONF3) generally have little confidence in their third recommendation. It would appear that they do not believe that this decision is right, trustworthy, but understand the normative pressure the money manager has to endure. Even if they are uncertain of making a "good" decision (i.e. optimal considering the information set), subjects respond to an exogenous constraint in order to preserve the reputation of the manager. 


\section{Testing of hypothesis}

In order to test the hypotheses, several questions in different parts of the document have tried to measure the following parameters: confidence in the personal analysis (Lichtenstein and Bearden [1989]), confidence in the analysis of analysts (Lichtenstein and Bearden [1989]), perceived reliability of information and conformism (Pettigrew [1958]).

〈INSERT TABLE 1 ABOUT HERE〉

The reliability of these scales is measured using Cronbach's alpha, which estimates the internal coherence of the elements of the scale. This alpha has been calculated for each scale as described in table 1.The scale measuring the confidence, in personal analysis as in that of the analysts, appears rather reliable, with an alpha of over 0.85 . However, the two other scales seem to be a little less reliable, though the coefficient is still acceptable for values between 0.62 and 0.92 (Nunally [1978]).

In order to test the hypotheses, two distinct statistical methods were used: simple linear regression and variance analysis. When variables were the results of scales, a simple regression model was used to link the subjects' level of confidence in their recommendation in stage 2 and 3, and the different scales. Hypotheses $\mathrm{H}_{4}$ and $\mathrm{H}_{5}$, whose variables are dichotomous, have been tested through a variance analysis. The proportion of the consensus can be high or low and an ANOVA is able to detect if the differences in the means for ICONF2 and ICONF3 are significant. In addition, an intra-subjects ANOVA, comparing the mean of the responses before (ICONF2) and after (ICONF3) the introduction of reputation, enables us to measure the influence of this constraint on the subjects' decisions.

As mentioned by Trueman [1990], the revision of the recommendation is probably under estimated insofar as changing one's opinion could reveal the weakness of the initial recommendation. If the consensus of analysts had been given within the information set of stage 1 , more herding might have been revealed ${ }^{9}$. The tests and the results are listed in table 
2. The regressions explain respectively 8.1 and 11.8 percent of the variance of ICONF2 and $\mathrm{ICONF}^{10}$.

$$
\text { 〈INSERT TABLE } 2 \text { ABOUT HERE〉 }
$$

The signs are coherent with the hypotheses (except for the $\mathrm{H}_{3}$ hypothesis in ICONF3 regression). However, only three coefficients are statistically significant according to the ttest: those concerning the a priori confidence in the personal capacities in both regressions, and the conformism variable in the second one.

\section{Herding behavior and a priori confidence}

The main statistically significant factor is the a priori confidence of the subjects in their own ability ${ }^{11}$. The perception of their capacity to analyze a firm proves to have an influence coherent with $\mathrm{H}_{2}$ : the more confidence the individual has in his abilities, the less he has a tendency to herd. This relation is true for both informational imitation $(t=-2.23, p<0.03$ for ICONF2) and for reputational herding ( $\mathrm{t}=-2.37, \mathrm{p}<0.02$ for ICONF3). A subject who is very confident in his capacities is less concerned by the consensus of analysts, whatever the nature of the group pressure.

This a priori confidence is very close to two other factors: an interest in financial markets and the fact of having already bought stocks. An ANOVA points out that herding behavior is also negatively correlated with experience of the market ${ }^{12}$. Subjects who had already bought stocks were less influenced by the informational dimension of analysts (stage 2). Reputation (stage 3) has more impact on their decision, even if most of them still prefer a fundamental choice. Moreover, a study of the correlation between ICONF2 and interest ${ }^{13}$ shows that the more the subjects are interested in financial markets, the less they are inclined to herd in stage 2 for informational reasons. Informational, like reputational herding, is therefore not only the result of the environment on the individual, but also linked to the personnal characteristics of the actors. 
The impact of a priori confidence seems to support the approaches based on the experience of actors, such as Chevalier and Ellison [1999] or Cudd and al. [2006] who show that younger money managers generally take fewer risky decisions and manage more conventional portfolios. The less experienced agents, who believe less in their own abilities, avoid making a decision which will reveal their incompetence, and to be the only one to suffer the consequences.

\section{The role of reputation}

One of the main contributions of this work is to introduce reputation, along with information, as a contributing factor in herding. This constraint significantly reinforces the tendency to herd $(\mathrm{F}(1,87)=14.32, \mathrm{p}<0.01)$. The decision is then not only based on the most profitable decision, but also on the pressure of clients and of the hierarchy on the manager. This change of optimization clearly shows that non financial constraints can also have a significant impact on investment decisions, and therefore on prices. Recently, Dasgupta and Prat [2005] or Ottaviani and Sorensen [2006] have presented the theoretical arguments of this hypothesis which is supported by the results of this experiment.

Reputation concerns subjects who are less confident in their capacities, and conformists according to Pettigrew's scale [1958]. Indeed, reputation seems to have more influence on conformist subjects who are more sensitive to normative pressure than others: $\mathrm{H}_{6}$ is validated by the data $(\mathrm{t}=1.66)$ at a 10 percent $^{14}$ significance level concerning a reputational herding. When the consensus is merely a source of information, conformist subjects are less sensitive to it.

More generally, one can observe a positive correlation ( $r=0.269 ; n=87 ; p<0.012)$ between the perceived importance of managers' competences and ICONF3. Therefore, the more this estimation is viewed as crucial, the more the subject will have a tendency to herd. Reputation could be considered as a continuous variable, according to the importance accorded to it by 
the subject. This experimental result is coherent with the study of Lütje [2005], who finds that German money managers who believe that herding can benefit their career adopt this behavior more easily, or at least assert more easily that they follow the trend.

\section{Other hypotheses}

Hypotheses $\mathrm{H}_{1}$ on the perceived reliability of the signal, $\mathrm{H}_{3}$ on the a priori confidence in the ability of analysts, and $\mathrm{H}_{4}$ on the proportion of analysts are not statistically significant. On information reliability, the coherence of the items of the scale may be low. The internal coherence of the scale, measured by Cronbach's alpha is, however, even lower with regard to conformism, for it reveals a 10 percent significance in the regression. The scale measuring the confidence of subjects in the ability of analysts $\left(\mathrm{H}_{3}\right)$ is not very convincing, since (in order to ensure homogenous answers) it is the same as that used to estimate the confidence in subjects' own ability. A blurring effect from the first scale is possible and may have led to dependant answers.

The reliability of the information signal $\left(\mathrm{H}_{1}\right)$ is more or less comparable for all the subjects, for company $\mathrm{X}$ and $\mathrm{Y}$, whether subjects herd or not. This seems to be coherent with the identical information received by subjects and reinforces the idea that information by itself is not the only factor of herding, but also the confidence the actor places in his own capacities. The influence of actual reliability of information is, however, not really tested by this experiment which focuses on perceived reliability.

The results about the proportion in the consensus $\left(\mathrm{H}_{4}\right)$ seem to support the conclusions of Kübler and Weizsäcker [2005]. Using a questionnaire, they found a positive relationship between the preceding number of individuals who made a choice and the probability that a new actor will adopt this choice. If the difference found is not significant, the results are coherent with the hypothesis: when the proportion of analysts is 6 to 1 to be opposed to the subject's evaluation (rather than 4 to 3 ), subjects prove to be slightly more influenced. The 
percentage of herding behavior rises to 34 percent for HERD2 and 56 percent for HERD3 versus respectively 23 and 45 percent with the lower proportion in the consensus.

Without a price mechanism, herding stemming from the speculation of other agents' behaviors (Shleifer and Summers [1990]) was not tested in this experiment. One subject admitted, however, to being influenced: "The propositions of analysts (rumors and information from acknowledged brokers) may greatly influence the decisions of investors." Following the analysts is then natural insofar as they have an impact on the market and will launch a trend. The belief in a price, result of the convergence of individual behaviors, leads this subject to herd rationally. Further works, studying this feedback relationship between subjects and prices ${ }^{15}$ more precisely, might enable us to better understand the speculative anticipations of actors.

\section{CONCLUSION}

The principal goal of this research was to generate some evidence of herding in a precise and renewed experimental framework, involving analysts' recommendations. Yes, herding behavior actually takes place, even in the binary setting of this experiment. Having to recommend buying or selling a stock, subjects were greatly influenced by the consensus of analysts opposed to their initial choice. In this experiment, half of them ignored their own interpretation of financial data to follow the consensus, which then often prevails over subjects' personal opinion. This result, which seems unprecedented, provides a clear understanding of the impact of herding in investment decisions. In some cases, people take their decision according to the behavior of others and put aside their own (sometimes even explicit) financial information, which is therefore not incorporated into prices. These micro results might have implications in macro anomalies like financial bubbles or trends in the stock market, and more generally when prices appear exaggerated compared to fundamental data. 
In addition, the aim of this paper has been to examine and measure some of the forces that lead money managers to follow the consensus in a way which seems impossible in the light of market data. Beyond the merely informative reason, the most significant and surprising result is the impact of reputation in the decision-making of subjects. They did not always herd because they considered the consensus to be really true, but also because of the pressure on managers' reputations. Some of them altered their choices simply as a protection mechanism against the risk of being "deviant", even if this risk is still hypothetical and does not affect them directly. This outcome underlines the major impact of social judgment on real portfolio managers, whose careers are really influenced by the pressure of their peers, clients and hierarchy (Scharfstein and Stein [1990], Avery and Chevalier [1999], Graham [1999]; Chevalier and Ellison [1999]; Dasgupta and Prat [2005], or Ottaviani and Sorensen [2006]).

This simple experiment is a first attempt to study informational and reputational factors in combination, and provides clear evidence that the self-confidence of the subject in his ability is probably the main counterweight to herding, whatever its origin. Conversely, operators who have some doubts in their abilities face two kinds of pressure to herd (i) in order to avoid making a bad decision, (ii) and to avoid making it alone. Such empirical results might enable us to better appreciate the social influence factors on individual decision-making in financial markets. 


\section{NOTES}

${ }^{1}$ And other works of Cipriani and Guarino [2005] or Kübler and Weizsäcker [2005].

${ }^{2}$ For Anderson and Holt [1998], two states are possible: A or B. The state is chosen randomly and is unknown by the subjects. If state $\mathrm{A}$ is chosen the urn used contains $\mathrm{p}$ balls $a$ and (1-p) balls $b$. The signal given by the ball is informative: the probability that a ball $a$ corresponds to state A is $\mathrm{p}$.

${ }^{3}$ From 2000 to 2005, "over-valued" firms had a price/book ratio over 3 and a P/E ratio over 50. "under-valued" firms had a P/E ratio under 12 and a price/book ratio under 1.

${ }^{4}$ The full questionnaire is available upon request.

${ }^{5}$ This financial summary reports some of the ratios already present in first stage, some are divided by share. The data for N-4 does not seem to give much more information. An a posteriori discussion with subjects showed that this summary was not really considered in their second recommendation.

${ }^{6}$ The questionnaires were distributed in order to alternate $\mathrm{X}$ and $\mathrm{Y}$ firms as well as the proportion of the

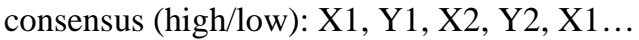

7 Two subjects changed their mind, and, after following the analysts, decided to come back to a fundamental choice. This might be interpreted as an opposition reaction to group pressure, but involved only two subjects.

${ }^{8}$ A chi-squared test gives for HERD2, $\chi^{2}=0.256 ; \mathrm{df}=1 ; \mathrm{p}<0.613$ and for HERD3 $\chi^{2}=0.729, \mathrm{df}=1 ; \mathrm{p}<0.393$.

${ }^{9}$ But the interpretation would have been difficult, since one cannot know which information the subjects used. In order to avoid this bias, two groups could be studied: one with and one without the consensus.

${ }^{10}$ As a comparison, Cote and Sanders (1997) explain 12 percent of the observed variance.

11 The confidence studied is an a priori confidence, which does not rely on the information set given to the subject. In fact, most of the models consider the confidence within the signal, exogenous to the agent, and not to individual intrinsic ability: the less informed actors herd the most. In the context of this experiment, there is no real informational asymmetry and the confidence measured is the confidence they attribute to their own capacities, independently of the information received.

${ }^{12} \mathrm{~F}(1,86)=7.887, \mathrm{p}<0.006$ for ICONF2, $\mathrm{F}(1,86)=5.386, \mathrm{p}<0.023$ for ICONF3.

${ }^{13}$ The correlation is -0.299 (resp. -0.081) between interest in financial markets and ICONF2 (ICONF3), with a signification of 0.01 (n.s.) for $\mathrm{n}=88$ (id.).

${ }^{14}$ To be more precise, $\mathrm{p}<0.10054310$.

${ }^{15}$ The trend, which may reveal speculative dynamics, is the most cited example of missing information (10 over 88) by subjects.

\section{REFERENCES}

Anderson, L., and Holt, C. "Information cascades in the laboratory". American Economic Review, Vol. 87, (1997), pp. 847862.

Aronson, E., Turner, J. A., and Carlsmith, J. M. "Communicator credibility and communication discrepancy as determinants of opinion change". Journal of Abnormal Social Psychology, Vol. 67, (1963), pp. 31-36.

Avery, C., and Chevalier, J. "Herding over the career". Economics Letters, Vol. 63, (1999), pp. 327-333.

Avery, C., and Zemsky, P. "Multidimensional uncertainty and herd behavior in financial markets". American Economic Review, Vol. 88, (1998), pp. 724-748.

Asch, S. "Effects of group pressure upon the modification and distortion of judgements". In Guetnow, H. (ed.) Group, leadership and men, Pittsburg, Carnegie Press, (1951), pp. 177-190.

Banerjee, A. “A simple model of herd behavior”. Quarterly Journal of Economics, Vol. 107, (1992), pp. 797-817.

Bikhchandani, S., Hirshleifer, D., and Welch, I. "A theory of fads, fashion, custom, and cultural change as informational cascades". Journal of Political Economy, Vol. 100, (1992), pp. 992-1026.

Blacke, R. R., Helson, H., and Mouton, J. S. "The generality of conformity behavior as a function of factual anchorage, difficulty of task and amount of social pressure". Journal of Personality, Vol. 25, (1957), pp. 294-305.

Bochner, S., and Insko, C.A. „Communicator discrepancy, source credibility, and opinion change”. Journal of Personality and Social Psychology, Vol. 4, (1966), pp. 614-621.

Chamley, C. Rational Herd: Economic Models of Rational Herding. Cambridge University Press, 2004.

Chevalier, J., and Ellison, G. "Career concerns of mutual fund managers". Quarterly Journal of Economics, Vol. 114, (1999), pp. 389-432.

Cipriani, M., and Guarino A. "Herd behavior in a laboratory financial market". American Economic Review, Vol. 95, (2005), $1427-1443$.

Cote, J., and Sanders, D. "Herding behavior: explanation and implications". Behavioral Research in Accounting, Vol. 9, (1997), pp. 20-45.

Crutchfield, R. "Conformity and character". The American Psychologist, Vol. 10, (1955), pp. 191-198. 
Cudd, M., Davis, H.E., and Eduardo, M. "Mimicking Behavior in Repurchase Decisions". Journal of Behavioral Finance, Vol. 7, (2007), pp. 222-230.

Dasgupta, A., and Prat, A. "Financial equilibrium with career concerns". Theoretical Economics, Vol. 1, (2006), pp. 67-93.

Devenow, A., and Welch, I. "Rational herding in financial economics". European Economic Review, Vol. 40, (1996), pp. 603-615.

Deutsch, M., and Gerard, H B. "A study of normative and informational social influences upon individual judgment". Journal of Abnormal Social Psychology, Vol. 51, (1955), pp. 629-636.

Graham, J. "Herding among investment newsletters: theory and evidence". Journal of Finance, Vol. 54, (1999), pp. 231-268.

Hong, H., Kubik, J., and Solomon, A. Security analysts career concerns and the herding of earnings forecasts. Rand Journal of Economics, Vol. 31, (2000), pp. 121-144.

Keynes, J.M. The general theory of employment, interest and money, London, MacMillan, 1936.

Kirman, A. “Ants, rationality and recruitment”. Quarterly Journal of Economics, Vol. 108, 1993, pp. 137-156.

Kübler D., and Weizsäcker G. (2005). "Are longer cascades more stable?" Journal of the European Economic Association, Vol. 3, pp. 330-339.

Lakonishok, J., Shleifer, A., and Vishny, R. W. "The impact of institutional trading on stock prices." Journal of Financial Economics, Vol. 32, (1992), pp. 23-43.

Lamont, O. "Macroeconomic forecasters and microeconomic forecasts". NBER, Working paper \#5284, (1995).

Lichtenstein, D., and Bearden, W. "Contextual influences on perceptions of merchant-supplied reference prices". Journal of Consumer Research, Vol. 16, (1989), pp. 55-66.

Lütje, T. To be good or to be better: asset managers' attitudes towards herding. Deutsche Asset Management and University of Hannover, Germany, (2005).

Northcraft, G., and Neale, M. "Experts, amateurs, and real estate: an anchoring and adjustment perspective on property pricing decisions". Organizational Behavior and Human Decision Processes, Vol. 39, (1987), pp. 84-99.

Nunally J. Psychometric theory. $2^{\text {nd }}$ Edition, McGraw Hill, New York, 1978.

Ottaviani, M., and Sorensen, P. "The strategy of professional forecasting”. Journal of Financial Economics, Vol. 81, (2006), pp. 441-466.

Ottaviani, M., and Sorensen, P., "Herd behavior and investment : comment". American Economic Review, Vol. 90, (2000), pp. 695-704.

Pettigrew, T. "Personality and sociocultural factors in intergroup attitudes: a cross-national comparison". Journal of Conflict Resolution, 2, (1958), pp. 29-42.

Scharfstein, D., and Stein, J. "Herd behavior and investment". American Economic Review, Vol. 80, (1990), pp. 465-479.

Sherif, M. The Psychology of Social Norms. New York, Harper, 1936.

Shiller, R. "Stock prices and social dynamics". Cowles Foundation Discussion Papers \#616, Cowles Foundation, Yale University, (1984).

Shleifer, A. and Summers, L.H. "The noise trader approach to finance”. Journal of Economic Perspectives, Vol. 4, (1990), pp. 19-33.

Trueman, B. "Reputation and performance among security analysts". Journal of Finance, Vol. 47, (1990), pp. 1181-36.

Weber, M. Economy and Society. Totowa, N.J., Bedminster, 1968.

Welch, I. "Herding among security analysts". Journal of Financial Economics, Vol. 58, (2000), pp. 369-396.

Wermers, R. "Mutual fund herding and the impact on stock prices". Journal of Finance, Vol. 54, (1999), pp. 581-622.

Wilder, D. A. "Perception of groups, size of opposition and social influence". Journal of Experimental and Social Psychology, Vol. 13, (1977), 253-268.

Wylie, S. "Fund manager herding: a test of the accuracy of empirical results using UK data". Journal of Business, Vol. 78, (2005), pp. 381-403. 


\section{APPENDIX : TABLES}

TABLE 1

Cronbach's alpha for the measurement of scales

\begin{tabular}{lcc}
\hline \multicolumn{1}{c}{ Scale } & Cronbach's alpha & Number of items \\
\hline Confidence in personal analysis & 0,906 & 4 \\
Confidence in the analysis of analysts & 0,852 & 4 \\
Perceived reliability of the information & 0,701 & 4 \\
Conformism & 0,660 & 5 \\
\hline
\end{tabular}

Note: Confidence in personal analysis and in the analysis of analysts is measured by the scale created by Lichtenstein and Bearden (1989) and conformism by selected items in Pettigrew's (1958) scale. 
TABLE 2

Test of the hypotheses- Summary

\begin{tabular}{|c|c|c|c|c|c|c|c|c|c|}
\hline \multirow[b]{2}{*}{ Hypotheses } & \multirow[b]{2}{*}{ Type of measure } & \multirow[b]{2}{*}{ Test } & \multirow{2}{*}{$\begin{array}{l}\text { Expected } \\
\text { sign }\end{array}$} & \multicolumn{2}{|c|}{ ICONF2 } & \multicolumn{4}{|c|}{ ICONF3 } \\
\hline & & & & Result & Signification & & Result & Sign & fication \\
\hline $\begin{array}{l}\mathrm{H}_{1} \text { : The lower the perception of reliability of } \\
\text { the private signal by the agent, the greater his } \\
\text { tendency to herd. }\end{array}$ & Likert Scale & $\begin{array}{l}\text { Linear } \\
\text { Regression }\end{array}$ & - & $\mathrm{t}=-0,3235$ & $\mathrm{p}<0,7471$ & & $t=-0,0279$ & $\mathrm{p}<$ & 0,9778 \\
\hline $\begin{array}{l}\mathrm{H}_{2} \text { : The lower the agent's a priori } \\
\text { confidence in his own capacities, the greater } \\
\text { his tendency to herd. }\end{array}$ & Likert Scale & $\begin{array}{l}\text { Linear } \\
\text { Regression }\end{array}$ & - & $\mathrm{t}=-2,2279$ & $p<0,0286$ & & $t=-2,3669$ & $\mathbf{p}<$ & $\mathbf{0 , 0 2 0 3}$ \\
\hline $\begin{array}{l}\mathrm{H}_{3} \text { : The higher the agent's a priori } \\
\text { confidence in the abilities of the analysts, the } \\
\text { greater his tendency to herd. }\end{array}$ & Likert Scale & $\begin{array}{l}\text { Linear } \\
\text { Regression }\end{array}$ & + & $\mathrm{t}=0,7402$ & $\mathrm{p}<0,4613$ & & $t=-0,0951$ & $\mathrm{p}<$ & 0,9244 \\
\hline $\begin{array}{l}\mathrm{H}_{4} \text { : The higher the majority of analysts agree } \\
\text { on a recommendation, the greater an agent's } \\
\text { tendency to herd. }\end{array}$ & $\begin{array}{l}\text { Comparison between } \\
\text { the two groups of } \\
\text { consensus : high/low }\end{array}$ & $\begin{array}{l}\text { inter-subjects } \\
\text { ANOVA }\end{array}$ & & $F(1,86)=$ & $\mathrm{p}<0,4105$ & $\mathrm{~F}(1,86)=$ & 1,3916 & $\mathrm{p}<$ & 0,2414 \\
\hline $\begin{array}{l}\mathrm{H}_{5}: \text { The more the agent tries to protect his } \\
\text { reputation, the greater his tendency to herd. }\end{array}$ & $\begin{array}{l}\text { Comparison between } \\
\text { the second and the } \\
\text { third recommendation }\end{array}$ & $\begin{array}{l}\text { intra-subjects } \\
\text { ANOVA }\end{array}$ & & & & $F(1,87)=$ & 14,3166 & $\mathbf{p}<$ & $\mathbf{0 , 0 0 0 3}$ \\
\hline $\begin{array}{l}\mathrm{H}_{6}: \text { The more the agent is proved to be } \\
\text { conformist, the greater his tendency to herd. }\end{array}$ & Likert Scale & $\begin{array}{c}\text { Linear } \\
\text { Regression }\end{array}$ & + & $\mathrm{t}=1,0943$ & $\mathrm{p}<0,2770$ & & $t=1,6609$ & $\mathbf{p}<$ & 0,1005 \\
\hline
\end{tabular}

Note. This table reports the results obtained with SPSS 12.0, using linear regression and ANOVA. The total number of subjects is $\mathrm{N}=88$. 